\title{
ESTIMATION OF OPTIMAL CROWN COVERAGE AND CANOPY SHAPE FOR SHADOW ESTIMATION ON TROPICAL MOIST BROADLEAF FOREST
}

\author{
T. Fujiwara ${ }^{\mathrm{a}, *}$, W. Takeuchi ${ }^{\mathrm{a}}$ \\ ${ }^{a}$ Institute of Industrial Science, The University of Tokyo, 4-6-1 Komaba, Meguro-ku, Tokyo, Japan \\ ftakumi@iis.u-tokyo.ac.jp
}

KEY WORDS: Structural parameter, Sentinel-2, Virtual forest, Reflectance simulation, Light use efficiency

\begin{abstract}
:
Shadow fraction is essential for improving the estimation of gross primary production, but it is difficult to be observed by satellite due to the diurnal variations. Therefore, it is necessary to estimate the $3 \mathrm{D}$ model with physical parameters by simulating virtual forest reflectance. In this study, we aim to estimate the optimal combination of canopy shape and Crown Coverage (CC) through simulating virtual forests reflectance. First, satellite-derived Tree Height (TH) and CC for virtual forests were compared with the ones obtained by Canopy Hight Model (CHM). Second, virtual forests with different CC and canopy shapes were created, and the reflectance and shadow fraction were simulated. The canopy shape used were cylinder, ellipsoid, half-ellipsoid, and inverted half-ellipsoid. Finally, the simulated reflectance and shadow fraction were validated with Sentinel-2 reflectance and shadow fraction from voxel model. Our results show that the mean TH is $15 \pm 2 \mathrm{~m}$, and the CC was increased from $10 \%$ to $60 \%$ in $10 \%$ intervals. TH and CC obtained from the satellite had the Root Mean Square Error (RMSE) of 5m and 40\%. Ellipsoid with 20\% CC shows the lowest RMSE and the smallest discrepancy for shadow fractions at the same sun position. However, other combinations were more accurate in estimating mean daily shadow fraction. This would be caused by only one image adopted in validation, which could be improved by using multi-season images in the future.
\end{abstract}

\section{INTRODUCTION}

Gross Primary Production (GPP) is one of the important components of carbon flux (Beer et al., 2010). Satellite remote sensing is useful for estimating GPP on a global scale, and the MODerate resolution Imaging Spectroradiometer (MODIS) GPP product (Running et al., 2004) has been widely used. For GPP estimation, the theoretical model devised by Monteith (1972) using absorbed photosynthetically active radiation and Light Use Efficiency (LUE) to estimate photosynthetic production has been used, but large uncertainties still remain in the global estimation. One of the uncertainties is the complexity of the tree forest 3D structure. Shadows are created by the geometric relationship between forest structure and sun position. Since shadow is a major determinant of leaf surface conductance (Brooks et al., 1997), it has been observed that shaded leaves are not light saturated (Knohl and Baldoccohi, 2008) and that diffuse light shows higher LUE (Kanniah et al., 2013). Therefore, both shade and sun leaves contribute to GPP, but their ratio is different (Gu et al., 2002). Therefore, incorporating their proportions in the GPP estimation will improve the accuracy.

Yan et al. (2017) estimated GPP with higher accuracy than before by using the clearance index (He et al., 2013) to estimate the ratio of diffuse to direct radiance, and the clumping index to take into account the sunlit and shaded leaves. Clumping index, however, is given a certain value for each tree species (Chen et al., 1999; He et al., 2013), but the shadow ratio varies with different structural parameters such as tree height and density even if the tree species is the same. In recent years, in addition to the clumping index, vegetation indices related to shadow fraction (Shadow index; Ono et al., 2015, Shadow Eliminated Vegetation Index; Jiang et al., 2019, Normalized Difference Canopy

\footnotetext{
* Corresponding author
}

Shadow Index; Xu et al., 2019) have been developed. It is expected that these indices used to estimate the shadow fraction independent of the tree species. However, since the ratio of direct to diffuse radiation is diurnal variation due to the shading effect of the forest structure ( $\mathrm{Li}$ et al., 1992), it is still questionable to estimate GPP using only the sun-shade component of satellite observation time. Hilker et al. (2008) reported that adding the mean daily shadow fraction calculated from a 3D model of the forest to the LUE improved the explanatory power. However, the method using satellite images can only observe at a certain time, so the mean daily shadow fraction cannot be calculated. One possible solution to this problem is to estimate the 3D shape of the forest and use it to estimate the mean daily shadow fraction.

In recent years, structural parameters such as Tree Height (TH) (Simard et al., 2011) and tree density (Crowther et al., 2015) have become globally available. Yang et al. (2017) developed a statistical approach to generate forest structure based on $\mathrm{TH}$ and tree density to create a highly accurate essential climate variables retrieval algorithm using the Monte Carlo-based Radiative Transfer (MCRT) models. The MODIS reflectance simulated by this approach was high accurate than the theoretical error of the atmospheric correction product. However, they used field measurement values, so it is expected that the error will increase when used only satellite-derived product is used because the product include errors. Therefore, when creating a virtual forest using only products, optimization of structural parameters is necessary. In addition, it is unclear whether the MCRT model can reproduce actual shadows, since shade and sun leaves are determined by random. Therefore, it is desirable to use a geometric optics model (Fan et al., 2015) to separate sunlit leaves from shaded leaves, but this model requires many parameters such as leaf shape and leaf density, some of which are difficult to estimate globally. On the other hand, Fujiwrara and Takeuchi (2020) developed a simple method for simulating 
reflectance using the shadow and leaf reflectance as parameters. The accuracy of the reflectance simulated by this method is highly dependent on that of the input shadow fraction. In other words, it was expected that the shadow ratio could also be estimated by selecting the optimal parameter that has the smallest error to the reflectance observed by the satellite from the combination of structural parameters obtained from the products.

An important parameter for creating a virtual forest is the canopy shape. This parameter needs to be assigned explicitly. In MCRT, the canopy shape is usually triangular pyramidal for coniferous forests and ellipsoid for broadleaf forests (Pisek and Chen, 2009; Ligot et al., 2016). Nelson et al. (1997) used several canopy geometries to simulate the airborne laser profiling response. The results showed that the different roughness of each canopy shape had a significant effect on the estimates. Since roughness also affects the shadow fraction, errors in shadow and reflectance due to differences in canopy shape should be evaluated and the optimal canopy shape should be selected. In particular, the difference is expected to be larger in forests where various canopy shapes are assumed, such as tropical forests.

The objective was to estimate the optimal structural parameters for shadow fraction estimation by comparing simulated reflectance and satellite-observed one using a virtual forests. In this study, we tackled the following three tasks: 1) to create several virtual forests using satellite-derived structural parameters, 2) to simulate the reflectance and compare with observed reflectance by satellite sensors, and 3) to simulate the shadow fraction and compare with that calculated from the 3D model. The target satellite sensor was Sentinel-2, because using a sensor with lower spatial resolution would increase the spatial heterogeneity of the forest. The structural parameters of interest were TH, Crown Coverage (CC) and crown shape. TH and CC were obtained from Global Forest Canopy Height (GFCH) 2019 (Potapov et al., 2021) and Global 2010 Tree Cover (GTC) (Hansen et al., 2013), respectively. The spatial resolution of both products is $30 \mathrm{~m}$ and GTC stores the CC of trees over 5 meters and GFCH stores the tree height in 1 meter units. However, creating a virtual forest by changing all combinations of TH, CC, and canopy shape would increase the computational cost. Therefore, we assumed that the value of $\mathrm{TH}$ did not have significant variation in the target forest. In other words, we created a virtual forest with different combinations of CC and canopy shape. The target forest was a tropical forest in Myanmar.

\section{METHODOLOGY}

\subsection{Flow of this study}

The flow of this study is shown in Figure 1 First, the TH and $\mathrm{CC}$ inputs to the virtual forest were determined by sampling, respectively. Those values were compared to the Canopy Hight Model (CHM) generated by Unmanned Aerial Vehicle (UAV) -Structure from Motion (SfM). Note that the measured values are not used to correct $\mathrm{TH}$ and $\mathrm{CC}$. The four tree canopy shapes used are cylinder, ellipsoid, half-ellipsoid, and inverted halfellipsoid, as shown in Figure 2. Second, a virtual forest is created based on those structural parameters, and reflectance and shadow are simulated. The canopy shape is not mixed, and the tree structure is determined based on the allometric equations. The canopy structure is TH, Canopy Length (CL), Canopy Radius (CR) and Diameter at Breast Height (DBH). Third, the simulated reflectance was evaluated using the Sentinel-2
Bottom of Atmosphere (BOA) reflectance. It was evaluated by Root Mean Square Error (RMSE) to the average value of each band. A test of normality was performed for all bands of sampled Sentinel-2 reflectance, and bands with p-values greater than 0.05 were used for evaluation. Finally, the simulated shadow fraction was evaluated by that calculated by the voxel model. The shadow fraction was evaluated by the difference of the mean values.

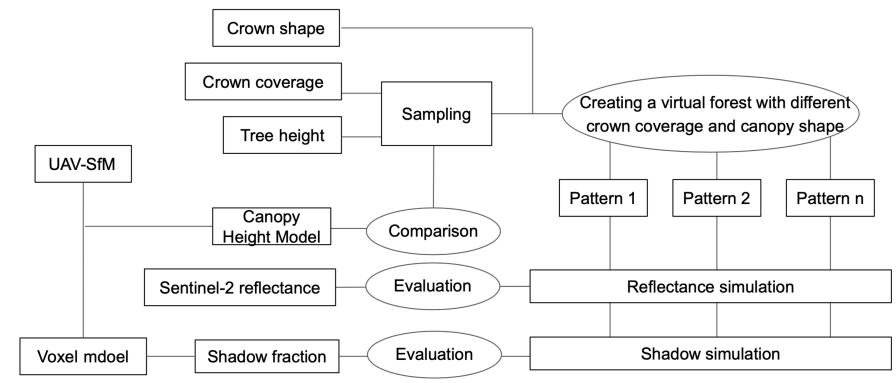

Figure 1. Flow chart of this study.

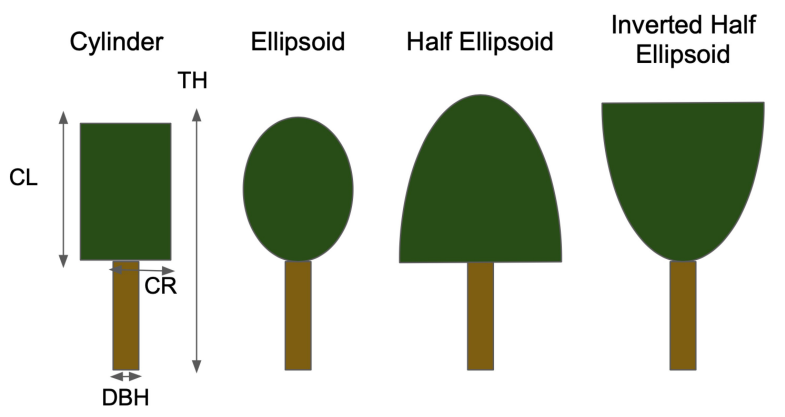

Figure 2. Canopy shapes used for creating the virtual forest. The canopy structure is Tree Height (TH), Canopy Length (CL), Canopy Radius (CR) and Diameter at Breast Height (DBH).

\subsection{Study forest}

The target forest is located on the Yangon Technological University $\left(16.8^{\circ} \mathrm{N}, 96.1^{\circ} \mathrm{E}\right)$, Myanmar. There were no mountains or other high elevations around, and the terrain was flat. The climate zone of the region is tropical monsoon climate. (Myanmar Information Management Unit, 2021). Several species were mixed together, and it was difficult to obtain allometric equations for each species. Therefore, we use the allometric equations developed by Antin et al. (2013) in their study of tropical rainforests in western India. The model was recalibrated to estimate $\mathrm{DBH}, \mathrm{CR}$ and $\mathrm{CL}$ using $\mathrm{TH}$.

$$
\begin{gathered}
D B H(\mathrm{~cm})=\exp \frac{\log T H-0.93}{0.63} \\
C R(m)=\frac{\exp (-0.12+0.63 \log D B H)}{2} \\
C L(m)=\frac{3 \exp (-0.90+1.84 \log D B H)}{2(-0.53+1.27 \log D B H)}
\end{gathered}
$$




\subsection{Creation of validation data for tree height, crown cov- erage and shadow ratio}

The target forest was observed by UAV on 21 September 2018. The camera zenith angle is 0 degrees and the altitude from the ground is about 100 meters. The point cloud was generated by SfM based on this data. The UAV used was Phantom 4 pro, and the software used for SfM was Pix4D. Geometric corrections were performed using GPS log data. Digital Surface Model (DSM) and Digital Terrain Model (DTM) were created respectively, and the CHM was generated by subtracting DTM from DSM. CHM is used for TH and CC validation. The spatial resolution of CHM was $30 \mathrm{~m}$. Since GTC is the percentage of tree cover above $5 \mathrm{~m}$, data with CHM above $5 \mathrm{~m}$ were used to validate $\mathrm{CC}$. The shadow ratio was calculated by converting the point cloud into a voxel model. The voxel size was determined so that each voxel has at least one point.

\subsection{Sentinel-2}

$\begin{array}{lccc}\text { Sentinel-2 B, level } & \text { 2A } \\ =\text { S2_SR/20191030T035901_20191030T040546_T46QHD }\end{array}$ ), acquired on September 30, 2019. Although about one year has passed since the UAV observation date, the forest condition is considered to be close because it is the same season. In this study, the normality of the reflectance of bands $2,3,4,5,6,7$, $8,8 \mathrm{~A}, 11$, and 12 obtained by the sample was investigated, and the bands with p-values greater than 0.05 were used.

\subsection{Setting of tree height and canopy coverage}

40 points were visually sampled for $\mathrm{CC}$ and $\mathrm{TH}$, respectively ( $0 \%$ coverage was excluded). The obtained $\mathrm{CC}$ values were converted to values in $10 \%$ increments, assuming that a few percent difference in $\mathrm{CC}$ does not affect reflectance or shading. The Weibull distribution (Siipilehto 2006) is usually used for $\mathrm{TH}$, but field measurements are required. Since the purpose of this study is to use only products, we did not assume that distribution. A normal distribution was assumed in this study. If the p-value of the sampled $\mathrm{TH}$ is greater than 0.05 , the $\mathrm{TH}$ of the forest is determined using the normal distribution. If the p-value is less than 0.05 , a normal distribution with the mean as the most frequent value and $2 \mathrm{~m}$ as the standard deviation is used.

\subsection{Create virtual forest}

The trees used were represented by voxel models. The size should match the voxel size of the UAV-SfM. The size of the forest was assumed to be $30 \mathrm{~m}$ square with a flat ground surface. The virtual forest is randomly arranged with trees to meet the coverage determined by sampling. It was assumed that if trees were placed completely randomly, the distance between adjacent trees may become very near in some cases. Therefore, tree locations were randomly placed to meet a canopy overlap of less than 10\%, same as Yang et al. (2017). 40 forest patterns were created for the same CC and canopy shape. Even the canopy shape was different, the tree positions were the same in the forests with the same pattern.

\subsection{Reflectance simulation model}

The method developed by Fujiwara and Takeuchi (2020) was used to simulate the reflectance. This method calculates the shielding factor for direct and diffuse radiation, defined as Cast Shadow (CS) and Self Cast Shadow (SCS), respectively, using a voxel model and the following equation. In this method, the leaf inclination is assumed 0 degrees, and multiple reflections and atmospheric effects are not considered. The Simple Model of the Atmospheric Radiative Transfer of Sunshine (SMARTS) code, version 2.9.5, was used to calculate the direct and diffuse irradiance.

$$
\rho(\lambda)=\frac{I_{d i r}(\lambda)(1-C S)+I_{d i f}(\lambda)(1-S C S)}{I_{d i r}(\lambda)+I_{d i f}(\lambda)} R(\lambda)
$$

where $\rho(\lambda)$ is reflectance observed by satellite, $\lambda$ is the wavelength, $I_{d i r}(\lambda)$ is direct horizontal irradiance $\left(\mathrm{W} / \mathrm{m}^{2} / \mu \mathrm{m}\right)$, CS is shielding ratio of $I_{d i r}(\lambda), I_{d i f}(\lambda)$ is diffuse horizontal irradiance $\left(W / \mathrm{m}^{2} / \mu \mathrm{m}\right), \mathrm{SCS}$ is shielding ratio of $I_{d i f}(\lambda), \mathrm{R}(\lambda)$ is spectral reflectance of the leaves and understory.

\subsection{Leaf and understory reflectance}

The spectral reflectance data for the simulation was selected from the ECOSTRESS Spectral Library (version 1.0). Prosopis articulata, a species also found in tropical South Asia, was used for leaf reflectance and Avena fatua for understory reflectance. The wavelength interval is $1 \mathrm{~nm}$.

\section{RESULT}

\subsection{Point cloud generation}

The average density of the generated point cloud was 10.38 points $/ \mathrm{m}^{3}$. The geometric correction was done by referring to the GPS log data without using ground control points. Therefore, geometric accuracy was not calculated. As mentioned in Section 2.3 , there must be at least one point in a voxel, so a voxel size of $50 \mathrm{~cm}$ was used.

\subsection{Comparison of TH and CC obtained by product and measurement}

The TH and CC of the 40 sampled points were compared with those generated from the CHM. Figure 3 shows the comparison results of $\mathrm{TH}$. The $\mathrm{TH}$ calculated using $\mathrm{CHM}$ ranged from $2.5 \mathrm{~m}$ to $13 \mathrm{~m}$, whereas the TH obtained from GFCH ranged from $7.5 \mathrm{~m}$ to $17.5 \mathrm{~m}$. The GFCH is higher than measured TH. The RMSE was $5.4 \mathrm{~m}$ and the maximum error was about $11 \mathrm{~m}$, which was an overestimation. Figure 4 shows the results of the $\mathrm{CC}$ comparison. Most of the measured $\mathrm{CC}$ values ranged from $60 \%$ to $100 \%$, but the CC values obtained from GTC ranged from $20 \%$ to $60 \%$. The RMSE was $40.3 \%$ and the maximum error was about $70 \%$, which was an underestimated.

\subsection{Reflectance simulation}

Since the p-value of TH obtained by sampling was $0.02<0.05$, the mean value of $\mathrm{TH}$ used for the virtual forest was the most frequent value of $15 \mathrm{~m}$, as described in Section 2.5. The minimum and maximum CC values were $10 \%$ and $60 \%$, respectively. 24 patterns of virtual forests were therefore created, with 6 different CC $(10 \%, 20 \%, 30 \%, 40 \%, 50 \%, 60 \%)$ and 4 different canopy shapes (cylinder, ellipsoid, half-ellipsoid, and inverted half-ellipsoid). For each pattern, 40 virtual forests were created to simulate the reflectance. 


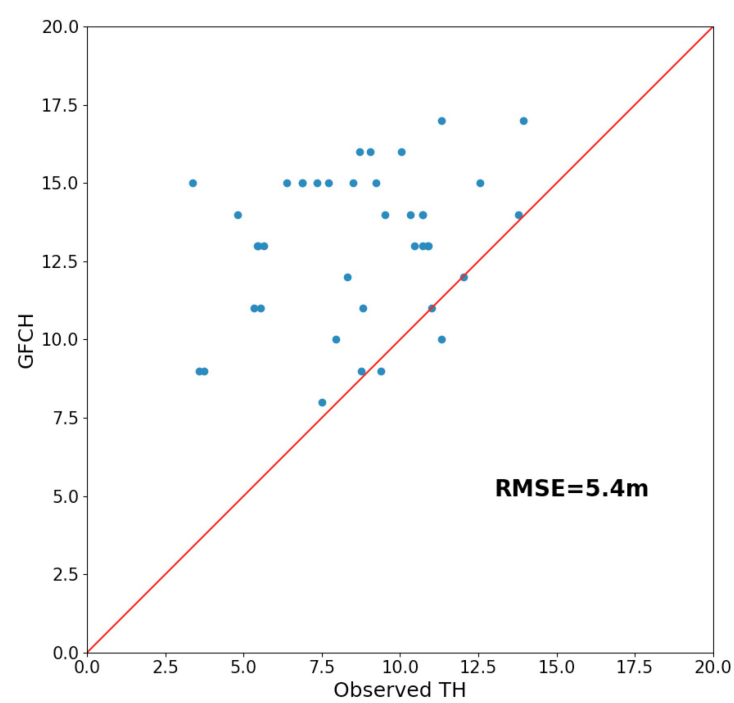

Figure 3. Comparison of measured $\mathrm{TH}$ and that obtained from GFCH. GFCH was overestimated compared to the measured TH. The RMSE was $5.4 \mathrm{~m}$.

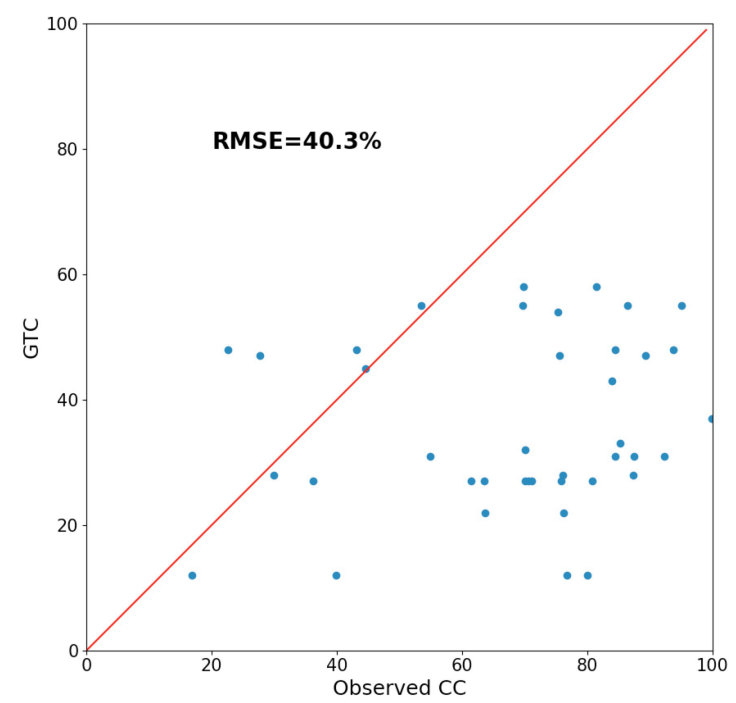

Figure 4. Comparison of measured $\mathrm{CC}$ and that obtained from GTC. GTC was underestimated compared to the measured CC. The RMSE was $40.3 \%$.

Figure 5 shows the virtual forests created using a cylinder and a half-ellipsoid for a crown shape when CC is $60 \%$. Green indicates the canopy, brown indicates the trunk, and black indicates the forest floor. The height and position of the trees are the same. Shadow images under the same sun position are also shown. It can be seen that the half-ellipsoid shape cause more shadows than the cylinder. Figure 6 shows the difference in the simulated reflectance when the CC is fixed at $60 \%$ and the tree canopy shape is changed. In the simulation method used (eq. 4), the reflectance is inversely related to the percentage of shadow. This means that for the same CC, the inverted halfellipsoid has the lowest shadow fraction, followed by the cylinder, ellipsoid and half-ellipsoid. Comparing the reflectance between inverted half-ellipsoid and the half-ellipsoid, the difference was about 1.3 times.

On the other hand, the Figure 7 shows the difference in the sim- ulated reflectance when the crown shape is fixed to an ellipsoid and the CC is changed from $0 \%$ to $60 \%$. The reflectance decreased as CC increased from $10 \%$ to $40 \%$, but the change from $40 \%$ to $60 \%$ was small. The reflectance at $10 \% \mathrm{CC}$ differs from that at $50 \%$ by about 1.3 times. It can be seen that the variation value of reflectance becomes smaller as $\mathrm{CC}$ increases.
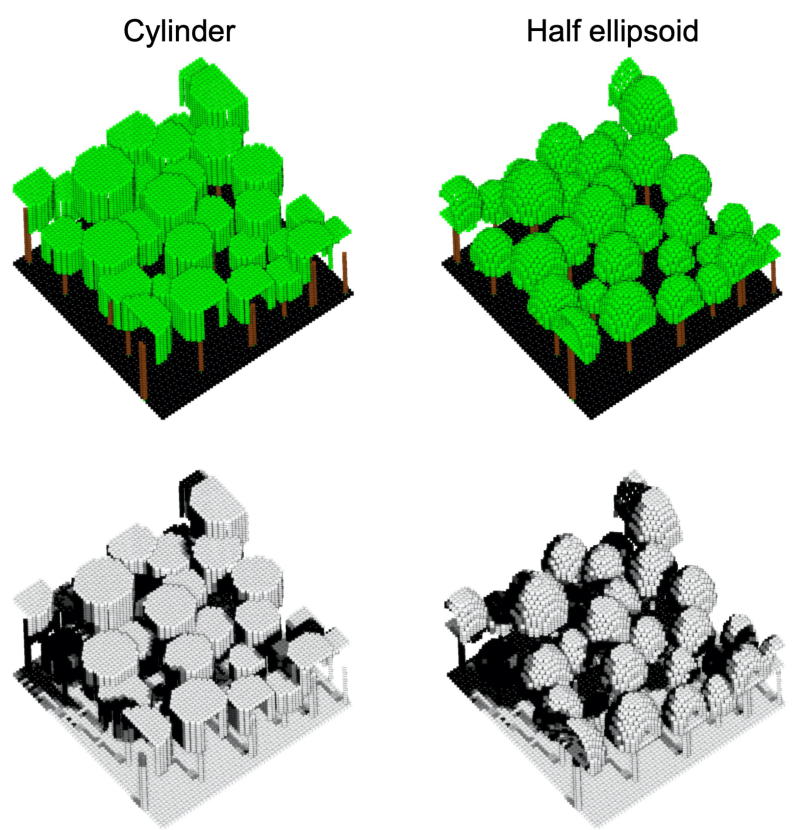

Figure 5. An example of a virtual forest using a cylinder and a half-ellipsoid as crown shapes. The height and position of the trees are the same in both forests, but the shadow ratio differs due to the difference in crown shape.

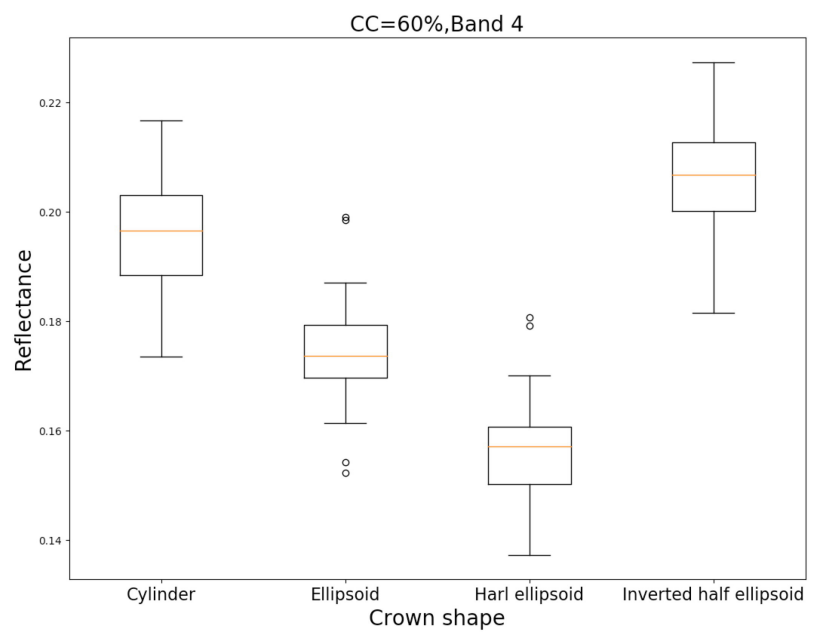

Figure 6. Reflectance difference due to canopy shape when CC is $60 \%$. The difference beteween an inverted half-ellipsoid and a half-ellipsoid is about 1.3 times.

\subsection{Evaluation of simulated reflectance}

As described in Section 2.1 the reflectance of the normality band is used to evaluate the result of reflectance simulation. The p-values of the sampled Sentinel-2 pixels and the simulated reflectance at each band were examined, and both were greater than the 0.05 significance level in band 6, 7, 8, 8A, and 11. The sample size is 40 . Table 1 shows the RMSE of the 


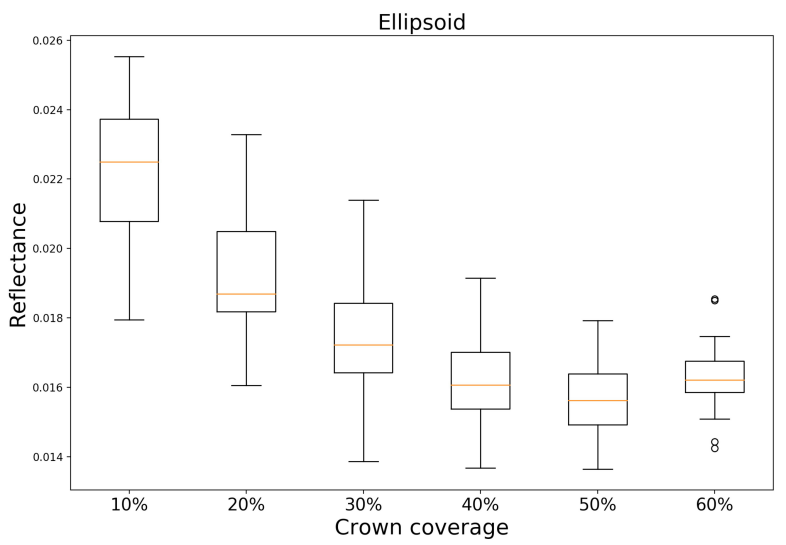

Figure 7. Reflectance changes with different $\mathrm{CC}$ in case of canopy shape is ellipsoid. The reflectance decreased from $10 \%$ to $40 \%$, but there was no significant change in reflectance between $40 \%$ and $60 \%$.

simulated reflectance to the Sentinel-2 BOA reflectance, calculated using those bands. The lowest RMSE was 0.025 when the crown shape was ellipsoid and the CC was $20 \%$. For all crown shapes, the RMSE was the lowest when CC was $20 \%$ and there was almost no difference. The RMSE decreased when CC increased from $10 \%$ to $20 \%$ and RMSE increased when CC increased from $20 \%$ to $60 \%$. The highest RMSE was 0.157 and the parameters of the virtual forest were half-ellipsoid canopy shape and $60 \% \mathrm{CC}$.

\begin{tabular}{ccccc}
\hline $\mathbf{C C}$ & $\mathbf{C}$ & $\mathbf{E}$ & HE & IHE \\
\hline $10 \%$ & 0.074 & 0.083 & 0.080 & 0.088 \\
$20 \%$ & 0.028 & 0.025 & 0.026 & 0.026 \\
$30 \%$ & 0.070 & 0.063 & 0.073 & 0.048 \\
$40 \%$ & 0.106 & 0.104 & 0.117 & 0.083 \\
$50 \%$ & 0.125 & 0.130 & 0.144 & 0.106 \\
$60 \%$ & 0.126 & 0.139 & 0.157 & 0.111 \\
\hline
\end{tabular}

Table 1. RMSE for Sentinel-2 BOA reflectance versus reflectance simulated using a virtual forest created based on each canopy shape and CC. (C:Cylinder, E:Ellipsoid, HE: Half-Ellipsoid and IHE: Inverted Half-Ellipsoid)

\subsection{Evaluation of simulated shadow ratio}

Table 2 shows the difference between the shadow fraction calculated using the voxel model and that calculated from the virtual forest at the same sun position. The solar azimuth angle is 136 degrees and the zenith angle is 26 degrees. The average shadow fraction, calculated using the voxel model, is 0.27 . The results showed that 0.017 was the smallest difference, the crown shape was half-ellipsoid and the CC was $20 \%$. This combination was consistent with the second lowest RMSE combination in Table 1 . The difference estimated from a virtual forest with a half-ellipsoid canopy shape and $60 \% \mathrm{CC}$, however, is 0.021 , a difference of only 0.004 . Furthermore, when cylinders or inverted half-ellipsoids are used for the crown shape, the difference is almost always smaller than 0.1 regardless of CC. For all crown shapes, the difference was the largest when CC is $50 \%$.

Table 3 shows the difference of the mean daily shadow fraction calculated using the voxel model and virtual forest. The mean daily shadow fraction is the average of the shadows calculated from the sun position at 8:00, 10:00, 12:00, 14:00, and
$16: 00$, and the result calculated using the voxel model is 0.34 . The smallest difference was 0.003 , the canopy shape was halfellipsoid, and the CC was $50 \%$. There was no tendency for the difference to change with respect to CC. Regardless of the canopy shape, the difference was about 0.2 in the virtual forest with $10 \%$ CC. In virtual forests where the crown shape is ellipsoid or half-ellipsoid and the CC is larger than $30 \%$, the difference is smaller than 0.1 .

\begin{tabular}{ccccc}
\hline $\mathbf{C C}$ & $\mathbf{C}$ & $\mathbf{E}$ & HE & IHE \\
\hline $10 \%$ & 0.073 & 0.079 & 0.067 & 0.103 \\
$20 \%$ & 0.031 & 0.033 & 0.058 & 0.017 \\
$30 \%$ & 0.081 & 0.095 & 0.131 & 0.030 \\
$40 \%$ & 0.102 & 0.135 & 0.181 & 0.053 \\
$50 \%$ & 0.104 & 0.156 & 0.208 & 0.062 \\
$60 \%$ & 0.054 & 0.128 & 0.190 & 0.021 \\
\hline
\end{tabular}

Table 2. The difference between the shadow fraction estimated from the voxel model and virtual forest at the same sun position. The average shadow fraction, calculated using the voxel model, is 0.27 .

\begin{tabular}{ccccc}
\hline $\mathbf{C C}$ & $\mathbf{C}$ & $\mathbf{E}$ & HE & IHE \\
\hline $10 \%$ & 0.225 & 0.224 & 0.208 & 0.245 \\
$20 \%$ & 0.158 & 0.149 & 0.121 & 0.186 \\
$30 \%$ & 0.117 & 0.096 & 0.060 & 0.147 \\
$40 \%$ & 0.103 & 0.069 & 0.026 & 0.132 \\
$50 \%$ & 0.091 & 0.044 & 0.003 & 0.114 \\
$60 \%$ & 0.104 & 0.040 & 0.010 & 0.120 \\
\hline
\end{tabular}

Table 3. The difference between the mean daily shadow fraction estimated from the voxel model and that estimated from the virtual forest. The average mean shadow fraction, calculated using the voxel model, is 0.34 .

\section{DISCUSSION}

Potapov et al. (2021) compared the accuracy of GFCH with the tree heights estimated by The Global Ecosystem Dynamics Investigation (GEDI) lidar and airborne laser scanner. The results showed that the overall RMSRs were $6.6 \mathrm{~m}$ and 9.07 $\mathrm{m}$, respectively. They also investigated the accuracy at each 1 $\mathrm{m}$ strata, and reported an underestimation of about $2 \mathrm{~m}$ for the present tree canopy coverage. Although we did not conduct a survey using the same method as theirs, the RMSE for the TH calculated by CHM was $5.4 \mathrm{~m}$ (Figure 3), which was better than their result. However, it is an overestimation not the underestimation. This is probably due to the training data used to generate the GFCH was limited in the tropical forest due to cloud cover (Potapov et al., 2021). We used the most frequent value of $15 \mathrm{~m}$ for the average $\mathrm{TH}$ of the virtual forest, but it turned out to be higher than the actual forest. In the future, it will be necessary to determine the tree height by referring to the location of the training data used for the GFCH and the error in each strata.

The CC estimated using GTC is about $40 \%$ (Figure 4 ) lower than that calculated from CHM. GTC provides CC for trees taller than $5 \mathrm{~m}$, and the height was calculated using the LiDAR (footprint size is $70 \mathrm{~m}$ ) of NASA's GLAS (Geoscience Laser Altimetry System) instrument aboard the IceSat-1 satellite (Hansen et al., 2013). This product has been used to estimate CC using Landsat or high spatial resolution images such as Quickbird as training data, but it has been reported that there is 
high uncertainty in the estimates. The $\mathrm{CC}$ used for the virtual forest used a value between the minimum and maximum values, but in the future, a higher CC value should be used.

It can be seen from Figure 5 and Figure 6 that a shape with a rounded top of the tree canopy produces fewer shadows and higher reflectance than a flat shape. This indicates that a round top has larger area to block sunlight. The fact that the reflectance is different even when the upper part of the canopy is the same, as in the case of an ellipsoid and a half-ellipse, or an inverted half-ellipse and a cylinder, indicates that the lower part of the canopy also affects the shadow ratio. From Figure 7 , it can be seen that the reflectance decreases as the CC increases from $10 \%$ to $40 \%$. This is due to the increase in the area where sunlight is shielded by the increase in the number of trees. On the other hand, from $40 \%$ to $60 \%$, the reflectance is almost constant, indicating that there is little change in the percentage of area that blocks sunlight. In this study, we assumed that the $\mathrm{TH}$ of the virtual forest follows a normal distribution with a mean value of $15 \mathrm{~m}$ and a standard deviation of $2 \mathrm{~m}$. As the standard deviation becomes larger, the roughness is expected to become even larger and the percentage of shadows larger. On the contrary, as the standard deviation becomes smaller, the roughness is expected to become smaller and the percentage of shadow becomes smaller.

Table 1 shows that the virtual forest with an ellipsoid canopy shape and CC is $20 \%$ has the smallest RMSE, but the difference with other canopy shapes when CC is $20 \%$ was small. Therefore, changing the reflectance of the leaves and understory used may change the optimal canopy shape. On the other hand, as $\mathrm{CC}$ increased, the difference in RMSE due to differences in canopy shape became larger. Nelson et al. (1997) suggested using ellipsoids when the tree canopy shape could not be identified, but when $\mathrm{CC}$ was high, it was expected that the error would be more significant if an appropriate tree canopy shape was not used. As shown in Table 2, the smallest difference between the shadow fraction estimated from the virtual forest and voxel model at the same sun position was 0.017. In that case, the suitable canopy shape was half-ellipsoid and the CC was $20 \%$, but there were several virtual forests where the difference was less than 0.05. Even when the virtual forest with the lowest RMSE in Table 1 ( canopy shape is ellipsoid and CC is 20\%) was used, the difference was 0.033 in Table 2 . This indicates that the optimal CC and canopy shape derived from the reflectance simulation can be used to estimate the shadows fraction of the forest. However, in Figure 4 CC derived from CHM ranges from $60 \%$ to $100 \%$, indicating a large difference from the simulation results. As shown in Figure 7 , in our simulations, the reflectance decreased with higher $\mathrm{CC}$ because of the increase in shadows. However, it was assumed that even at high CC, if $\mathrm{TH}$ variation is small, roughness would be smaller and shadows would be less. In this study, the standard deviation of TH in the virtual forest was fixed at $2 \mathrm{~m}$, so the forest in such a case was not considered. As shown in Table 3, the virtual forest with the smallest difference in daily shadow fraction had a half-ellipsoid crown shape and a CC was $50 \%$. The virtual forest with the lowest RMSE in Table 1 had a difference of 0.149 , which was larger than the difference in Table 2 . The reason seems to be that the sun position was limited because only one scene Sentinel2 image was used for the validation. Therefore, we expect to improve the accuracy by adding images from different seasons and other satellite images such as Landsat and Aster to the validation.

\section{CONCLUSION}

The objective of this study was to estimate the optimal CC and canopy shapes for shadow fraction estimation through reflectance simulation. CHM generated from UAV-SfM, Sentinel-2 $\mathrm{BOA}$ reflectance and voxel models were used to validate $\mathrm{TH}$ and $\mathrm{CC}$, reflectance simulation, and shadow fraction, respectively. RMSE of TH and CC obtained from each product was $5 \mathrm{~m}$ and $40 \%$ to those value calculated from CHM, respectively. $\mathrm{TH}$ tended to overestimate and $\mathrm{CC}$ tended to underestimate. The average $\mathrm{TH}$ of the virtual forest was $15 \mathrm{~m}$ with a standard deviation of $2 \mathrm{~m}$. The $\mathrm{CC}$ was increased from $10 \%$ to $60 \%$ in $10 \%$ intervals. A total of 24 patterns of virtual forests were created, with 40 forests per pattern. When the CC was fixed and only the crown shape was changed, the highest reflectance was obtained for the inverted half-ellipsoid and the lowest for the half-ellipsoid. When the crown shape was fixed and the CC was changed, the reflectance decreased from $10 \%$ to $40 \%$. The combination of canopy shape and $\mathrm{CC}$ that resulted in the lowest RMSE for Sentinel-2 BOA reflectance was inverted halfellipsoid and $20 \%$. This combination was also 0.03 difference to the shadow fraction calculated from the voxel model. However, CC calculated from the CHM ranged from $60 \%$ to $100 \%$, so the difference with $\mathrm{CC}$ estimated was large. The reason for this is that even when CC is high, a small variation in TH may result in a less shadow, which has not been taken into account in this study. In estimating mean daily shadow fraction, other combinations were more suitable than the best combination to Sentinel-2 reflectance. This is due to the reflectance simulation, where only one scene Sentinel-2 image was used for validation. In this target forest, by optimizing CC and canopy shape through reflectance simulation, it was possible to estimate the shadow fraction at the time of observation by the satellite sensor, but CC was different from real one, and it was found that the variation of $\mathrm{TH}$ also needed to be optimized. In addition, the use of multiple time period images and other satellite images is expected to improve the estimation accuracy of the mean daily shadow fraction.

\section{REFERENCES}

Antin, C., Plissier, R., Vincent, G., Couteron, P., 2013. Crown allometries are less responsive than stem allometry to tree size and habitat variations in an Indian monsoon forest. Trees, 27, 1485-1495. doi.org/10.1007/s00468-013-0896-7.

Beer, C., Reichstein, M., Tomelleri, E., Ciais, P., Jung, M., Carvalhais, N., Rodenbeck, C., Arain, M.A., Baldocchi, D., Bonan, G.B., Bondeau, A., Cescatti, A., Lasslop, G., Lindroth, A., Lomas, M., Luyssaert, S., Margolis, H., Oleson, K.W., Roupsard, O., Veenendaal, E., Viovy, N., Williams, C., Woodward, F.I., Papale, D., 2010. Terrestrial gross carbon dioxide uptake: global distribution and covariation with climate. Science, 329, 834-838. doi: 10.1126/science.1184984.

Brooks, J.R., L.B. Flanagan, G.T. Varney., J.R. Ehleringer., 1997. Vertical gradients in photosynthetic gas exchange characteristics and refixation of respired $\mathrm{CO} 2$ within boreal forest canopies. Tree Physiology, 17, 1-12. doi.org/10.1093/treephys/17.1.1.

Chen, J. M., Liu, J., Cihlar, J., Goulden, M. L. 1999. Daily canopy photosynthesis model through temporal and spatial scaling for remote sensing applications. Ecological Modelling, 124, 99-119. https://doi.org/10.1016/S0304-3800(99)00156-8. 
Crowther, T.W., Glick, H.B., Covey, K.R., Bettigole, C., Maynard, D.S., Thomas, S.M., Smith, J.R., Hintler, G., Duguid, M.C., Amatulli, G.; et al., 2015. Mapping tree density at a global scale. Nature, 525, 201-205. doi.org/10.1038/nature14967.

Fan, W., Li, J., Liu, Q., 2015. GOST2: The improvement of the canopy reflectance model gost in separating the sunlit and shaded leaves. it IEEE J. Sel. Top. Appl. Earth Obs Remote Sens, 8, 1423-1431. doi.org/10.1109/JSTARS.2015.2413994.

Fujiwara, T., Takeuchi, W., 2020. Simulation of Sentinel-2 Bottom of Atmosphere Reflectance Using Shadow Parameters on a Deciduous Forest in Thailand. ISPRS Int. J. Geo-Inf. 9(10), 582. doi.org/10.3390/ijgi9100582.

Gu, L., Baldocchi, D., Verma, S.B., Black, T.A., Vesala, T., Falge, E.M., Dowty, P.R., 2002. Advantages of diffuse radiation for terrestrial ecosystem productivity. J. Geophys. Res. 107, ACL 2-1-ACL 2-23. doi.org/10.1029/2001JD001242.

Hansen, M. C., P. V. Potapov, R. Moore, M. Hancher, S. A. Turubanova, A. Tyukavina, D. Thau, S. V. Stehman, S. J. Goetz, T. R. Loveland, A. Kommareddy, A. Egorov, L. Chini, C. O. Justice, Townshend, J.R.C., 2013. High-resolution global maps of 21st-century forest cover change. Science, 342, 850-853. doi.org/10.1126/science.1244693.

He, M., Ju, W., Zhou, Y., Chen, J., He, H., Wang, S., Wang, H., Guan, D., Yan, J., Li, Y., Hao, Y., Zhao., F., 2013. Development of a two-leaf light use efficiency model for improving the calculation of terrestrial gross primary productivity. Agric. For. Meteorol. 173, 28-39. doi.org/10.1016/j.agrformet.2013.01.003.

Hilker, T., Coops, NC., Schwalm, C. R,, Jassal, R.S., Black, T. A., Krishnan, P., 2008. Effects of mutual shading of tree crowns on prediction of photosynthetic light-use efficiency in a coastal Douglas-fir forest. Tree Physiology, 28, 825-834. doi.org/10.1093/treephys/28.6.825.

Jiang, H., Wang, S., Cao, X., Yang, C., Zhang, Z., Wang, X., 2018. A shadow-eliminated vegetation index (SEVI) for removal of self and cast shadow effects on vegetation in rugged terrains. Int. J. Dig.Earth, 12, 1013-1029. doi.org/10.1080/17538947.2018.1495770.

Kanniah, K. D., Beringer, J., Hurley, L., 2013. Exploring the link between clouds, radiation, and canopy productivity of tropical savannas. Agricultural and Forest Meteorology, 182, 304313. doi.org/10.1016/j.agrformet.2013.06.010.

Knohl, A., Baldocchi, D. D., 2008. Effects of diffuse radiation on canopy gas exchange processes in a forest ecosystem. J. Geophys. Res. -Biogeosci, 113(G2), G02023. doi.org/10.1029/2007JG000663.

Li, X., Strahler, A.H., 1992. Geometric-optical bidirectional reflectance modeling of the discrete crown vegetation canopy: effect of crown shape and mutual shadowing. IEEE Trans. Geosci. Remote Sens, 30, 276-292. doi.org/10.1109/36.134078.

Ligot, G., Ameztegui, A., Courbaud, B., Coll, L., Kneeshaw, D., 2016. Tree light capture and spatial variability of understory light increase with species mixing and treesize heterogeneity. Can. J. For. Res, 46, 968-977. doi.org/10.1139/cjfr-2016-0061.
Monteith, J. L. 1972. Solar radiation and productivity in tropical ecosystems. Journal of Applied Ecology, 9, 744-766. doi.org/10.2307/2401901.

Myanmar Information Management Unit, https:/ /themimu.info/sites/themimu.info/files/documents/ Map_Koppen-Geiger_Climate_Zones_of_Myanmar_19862010_MIMU1548v01_17Jan2018_A4.pdf （ 2021/01/10 accessed).

Nelson, R., 1997. Modeling forest canopy heights: The effects of canopy shape. Remote Sens. Environ, 60, 327-334. https://doi.org/10.1016/S0034-4257(96)00214-3.

Ono, A., Takeuchi, W., Hayashida, S. 2015. Estimation of forest canopy height using MODIS shadow index. 36th Asian conference on remote sensing (ACRS): Manilla, Philippines, Oct. 20, 2015.

Potapov, P., Li, X., Hernandez-Serna, A., Tyukavina, A., Hansen, M.C., Kommareddy, A., Pickens, A., Turubanova, S., Tang, H., Silva, C.E., Armston, J., Dubayah, R., Blair, J.B., Hofton, M., 2021. Mapping global forest canopy height through integration of GEDI and Landsat data. Remote Sens. Environ, 253, 112165. doi.org/10.1016/j.rse.2020.112165.

Pisek, J., Chen, J. M., 2009. Mapping forest background reflectivity over North America with multi-angle imaging SpectroRadiometer (MISR) Data. Remote Sens. Environ, 113, 24122423. doi.org/10.1016/j.rse.2009.07.003.

Running, S.W., Nemani, R.R., Heinsch, F.A., Zhao, M.S., Reeves, M., Hashimoto, H., 2004. A continuous satellite-derived measure of global terrestrial primary production. Bioscience, 54, 547-560. doi.org/10.1641/00063568(2004)054[0547:ACSMOG]2.0.CO;2.

Simard, M., Pinto, N., Fisher, J.B., Baccini, A., 2011. Mapping forest canopy height globally with spaceborne lidar. J. Geophys. Res: Biogeosci, 116, 1-12. doi.org/10.1029/2011JG001708.

Siipilehto J., 2006. Height distributions of Scots pine sapling stands affected by retained tree and edge stand competition. Fennica, 40(3), 473-486. doi.org/10.14214/sf.331.

Xu N., Tian J., Tian Q., Xu K., Tang S., 2019. Analysis of Vegetation Red Edge with Different Illuminated/Shaded Canopy Proportions and to Construct Normalized Difference Canopy Shadow Index. Remote Sensing, 11(10), 1192. doi.org/10.3390/rs11101192.

Yan, H., Wang, S. Q., Yu, K. L., Wang, B., Yu, Q., Bohrer, G., Billesbach, D., Bracho, R., Rahman, F., Shugart, H. H., 2017. A novel diffuse fraction-based two-leaf light use efficiency model: an application quantifying photosynthetic seasonality across 20 Ameriflux tower sites. J. Adv. Model. Earth Sys, 9, 2317-2332, doi.org/10.1002/2016MS000886.

Yang, W., Kobayashi, H., Chen, X., Nishida, N.K., Suzuki, R., Kondoh, A., 2017. Modeling three-dimensional forest structures to drive canopy radiative transfer simulations of bidirectional reflectance factor. Int. J. Digital Earth, 1-20, doi.org/10.1080/17538947.2017.1353146. 